\title{
Comparison of Satellite Orbit Ephemerides for Use in GPS Meteorology
}

\author{
Michal Kačmařík ${ }_{1}$, Pavla Skřivánková \\ 1 Institute of Geoinformatics, Faculty of Mining and Geology, VŠB-Technical University of Ostrava, 17. \\ listopadu 15, 708 00, Ostrava-Poruba, Czech Republic, michal.kacmarik@vsb.cz \\ 2 Czech Hydrometeorological Institute, Remote Sensing Section, Na Šabatce 17, 143 06, Praha 4, Czech \\ Republic, skrivankova@chmi.cz
}

\begin{abstract}
This paper discusses GPS (Global Position System) meteorology. The research presented is based on a comparison of values of precipitable water vapour PWV, based on GPS measurements using final and predicted ephemerides of satellite orbits. We analysed recent year's improvement in predicting ephemerides. We compared the data outputs from a radiosonde using GPS receiver measurements directly from the meteorological station from which the radiosondes were launched. The results indicate a high quality of the predicted ephemerides. This finding makes predicted ephemerides highly usable for near real-time estimations of PWV. To use PWV in meteorological forecast applications, this high speed of PWV values supply is necessary.
\end{abstract}

Keywords: GPS meteorology, precipitable water vapour, radiosonde, satellite orbits

\section{Introduction}

Several researchers have shown that the GPS system is useful for the estimation of troposphere parameters (Bevis et al., 1992, Duan et al., 1996). Based on knowledge of the values of the total signal delay in the zenith angle of the GPS receiver and the values of the atmospheric temperature and air pressure at the measurement, we are able to estimate the precipitable water vapour (PWV) in the atmosphere, with high accuracy. The PWV significantly influences weather conditions. Thus, to effectively use the PWV values for weather forecasting applications, it is necessary to have these values as soon as possible.

The ephemerides of satellite orbits have a significant impact on a precise estimation of the ZTD (zenith total delay) and the most accurate final products calculated from observations are available approximately two weeks after the particular measurement. As a result, less-quality orbits have to be used for the near real-time data processing. Generally, the most suitable products of this type are the predicted ultra rapid ephemerides supplied by the IGS (International GNSS Services) since March 5 ${ }^{\text {th }}, 2000$ (Springer et al., 2001). The data files are published with a three-hour delay, and they are calculated for a 48-hour interval (24 hours of observed ephemerides and the following 24 hours of predicted ephemerides). Thus, the files are available four times a day. Previous research indicated that these files were useful for PWV estimation. However, the PWV values were less accurate when the estimates were used than when the final ephemerides were used (Douša, 2001, Ge et al., 2000, Springer et al., 2001). The objective of this work is to determine if the quality of the predicted ephemerides has improved.

Currently, the most commonly used method for the precipitable water vapour estimation in the atmosphere is using a radiosonde fixed under a weather balloon to collect measurements. Using the results measured by this method, the quality of GPS measurements results can be compared. However, there are some limitations to this method. The GPS receiver is often several kilometres, sometimes even tens of kilometres, away from the weather station from which the radiosondes are launched. The atmospheric conditions can differ greatly over these distances. Furthermore, the wind can move a weather balloon up to $150 \mathrm{~km}$ away from the place it was launched, which can further negatively influence the comparison.

In this paper, we discuss the results of the GPS meteorology using different ephemerides and results measured using a radiosonde. The GPS receiver was placed directly in the weather station from which the radiosondes were launched. 


\section{Basics of GPS ZTD Processing}

There exist two main techniques how to acquire ZTD values from GPS measurements. The first one requires a whole network of GPS receivers and uses a double-differencing technique to resolve ambiguities and minimize errors associated with precise GPS data processing. The second technique, called Precise Point Positioning (PPP), requires only measurements from the only receiver for its location the ZTD are needed, but the ambiguities remains unresolved and the quality of the results tends to be lower generally. In this study the first technique is used.

Zenith total delay can be separated into a large quantity which is caused by the hydrostatic part of the atmosphere (zenith hydrostatic delay) and smaller quantity caused by the wet part of the atmosphere (zenith wet delay). The hydrostatic part is dependent mainly on the surface pressure and the wet part on the water vapour. During the processing of GPS data both of these components of the total delay are modelled.

For the ZTD estimations are used measurements from permanent reference stations equipped with geodetic GPS receivers. The position of such stations is known very precisely and is practically stationary in time. The unprocessed data measured at these stations are being saved in Receiver Independent Exchange Format (RINEX) files. The RINEX format consists of several ASCII file types. Generally, the Observation Data Files contains phase and pseudo-range measurements, the Navigation Message Files contains ephemerides broadcasted by satellites and optional Meteo Data Files contains atmospheric temperature and air pressure measured by weather station situated near the GPS receiver.

\section{Specification of a Network of Reference Stations}

For the ZTD processing, a network was established between the GPS receiver located at the weather station in Praha-Libuš and the ten other reference stations located in the Czech Republic and surrounding countries. The shortest distance between the stations is approximately $26 \mathrm{~km}$, and the longest distance is $470 \mathrm{~km}$. The station with the lowest elevation is situated $203 \mathrm{~m}$ above sea level, and the station with the highest elevation is $1,347 \mathrm{~m}$ above sea level.

The GPS receiver located at the weather station in Praha-Libuš is presented as CHMU in this paper. A tripodmounted geodetic Topcon Hiper GD receiver was used to take measurements in static mode with a 30-s sampling rate. The original reference point of the GPS receiver was determined by averaging RINEX file values, which were saved at 1-hr intervals. The exact position was later calculated using the Bernese GPS Software application (Dach et al., 2007). The GPS receiver was temporary stabilized at this location only for purpose and time of this study.

The reference station GOPE which is used for the evaluation of results from CHMU is situated near Prague at Geodetic Observatory Pecny. GOPE is also of the EPN (EUREF Permanent Network) analysis and data centres.

\section{Data Evaluation}

Data from 23 - 27 November 2009 were evaluated. The quality of the available ephemerides data was evaluated in three ways. The first method used the final ephemerides of the IGS service, the second used the predicted part of the ultra rapid ephemerides of the IGS service, and the third used ephemerides taken from the navigation RINEX files of GPS receivers. When the predicted ephemerides were used, the day-long data file consisted of four individual sections and the latest available ephemerides were used. The Bernese GPS Software version 5.0 was used to calculate the ZTD values and the characteristics for particular calculations are presented in Table 1. The Saastamoinen model along with values of atmospheric pressure and air temperature were used for the PWV estimation. Atmospheric values for CHMU and GOPE were measured at the weather stations located at the same place as the receivers.

During the evaluation of predicted ephemerides, there was made a setting which would exclude orbits with an exponent of accuracy higher than seven. The orbit accuracy exponent represents orbital error for a respective satellite in an entire orbit file. The orbital error is computed as $2^{\exp } \mathrm{mm}$ and should represent one standard deviation (SD). For an example if the exponent of accuracy is 7 , the orbital error is $2^{7} \mathrm{~mm}$ which approximately equals to $13 \mathrm{~cm}$. Data pre-processing to filter problematic orbits out of ephemerides files and improve the quality of ephemerides was not used; however, the standard Bernese tools were used to pre-process the data. Such filtering methods to improve data quality have been described in other studies (Baltink et al., 2002, Douša, 2001, 
Ge et al., 2000). But finally it has to be mentioned, that in this study, an accuracy exponent greater than 6 did not appear in the processed predicted ephemerides.

\begin{tabular}{|l|c|c|c|}
\hline & \multicolumn{1}{|c|}{$\begin{array}{c}\text { IGS } \\
\text { final }\end{array}$} & $\begin{array}{c}\text { IGS Ultra rapid } \\
\text { predicted }\end{array}$ & $\begin{array}{c}\text { Ephemeris from } \\
\text { navigation RINEX files }\end{array}$ \\
\hline Sampling rate & \multicolumn{3}{|c|}{$30 \mathrm{~s}$} \\
\hline Elevation cut-off angle & \multicolumn{3}{|c|}{$5^{\circ}$} \\
\hline Mapping function & \multicolumn{3}{|c|}{ IGS model applied } \\
\hline Phase Centre Correction & \multicolumn{3}{|c|}{ Applied } \\
\hline Ocean Loading & \multicolumn{3}{|c|}{ Double differences } \\
\hline Observables & \multicolumn{3}{|c|}{30 min } \\
\hline ZTD estimation interval & $\begin{array}{c}\text { IGS } \\
\text { final }\end{array}$ & $\begin{array}{c}\text { IGS ultra-rapid } \\
\text { predicted }\end{array}$ & $\begin{array}{c}\text { IGS ultra-rapid } \\
\text { predicted }\end{array}$ \\
\hline Pole information & $\begin{array}{c}\text { CODE } \\
\text { 30-day }\end{array}$ & No & No \\
\hline Differential Code Bias information & solution & No & No \\
\hline Ionospheric maps & CODE & No & \multicolumn{3}{|c|}{. } \\
\hline
\end{tabular}

Table 1: Basic Characteristics of ZTD Estimation in Bernese GPS SW

\section{Comparison of Results from GPS and Radiosonde Measurements}

Fig. 1 shows a comparison of the PWV values based on processing of final ephemerides with predicted ephemerides and measurements made by radiosondes (RDS). With few exceptions, the GPS and RDS results correspond well. Importantly, a comparison of the results of both types of ephemerides processing shows that the outputs do not differ. According to the statistical processing, the results presented in the Table 2 show no statistical difference between the two sources of data at the 5\% level of significance. Furthermore, the predicted ephemerides generate even data that are less scattered with a lower root mean square error (RMSE). A parametric paired t-test was used to determine if the average of the differences equalled zero for the tests described above. If the two GPS receiver measurements taken at the time limits (i.e., those taken at 23.11. 12:00 and 27.11. 12:00) are excluded, the results slightly improve. This is most probably caused because there were no GPS measurements before/after those times which would improve the solution of ZTD modelling.

Although the weather balloons and radiosondes were launched from the weather station in Praha-Libuš at 6hour intervals, two instances in Fig. 1 are shown where the PWV values of radiosondes were determined at 30minute intervals (25.11. 1:00 and 26.11. 1:00). This result occurred because the weather balloon burst before it reached the specified standard pressure of $100 \mathrm{hPa}$. Thus, another balloon was launched. Considering that most of the precipitable water vapour is found in the troposphere under the tropopause level and the first balloons reached this height without problems, the measurements at these time points were included for further processing. 


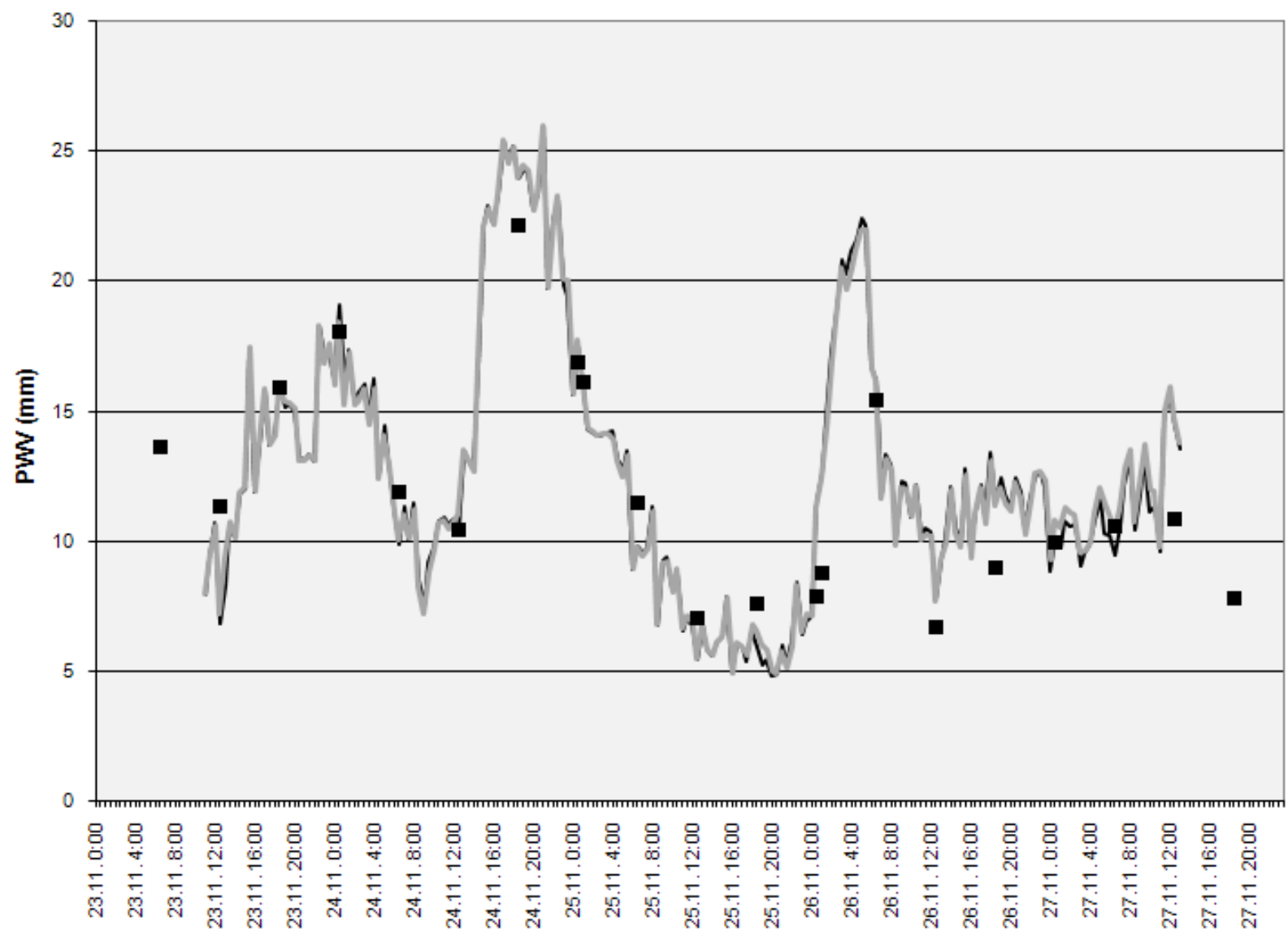

Time

\begin{tabular}{|lll|}
\hline G GPSIGS final & a \\
& GDSIGU predicted \\
\hline
\end{tabular}

Fig. 1: PWV content in the atmosphere based on estimations from GPS measurements and from radiosondes at the weather station in Praha-Libuš, 23 - 27 November, 2009

\begin{tabular}{|c|r|r|r|r|c|}
\hline & Bias, $\mathrm{mm}$ & SD, mm & $\begin{array}{l}\text { RMSE, } \\
\mathrm{mm}\end{array}$ & Pairs & $\begin{array}{c}\text { P-value } \\
\text { t-test }\end{array}$ \\
\hline GPS final vs. predicted & -0.020 & 0.307 & 0.307 & 197 & \\
\hline GPS final vs. RDS & 0.348 & 2.197 & 2.166 & 19 & \multirow{2}{*}{0.12} \\
\hline GPS predicted vs. RDS & 0.494 & 2.045 & 2.050 & 19 & 0.12 \\
\hline
\end{tabular}

Table 2: Statistical Processing of Comparison of PWV Estimation Methods. Bias corresponds to mean difference between two time series, $S D$ is the standard deviation of the difference between two time series and RMSE is the root mean square of the differences between two time series

A comparison of our results with published values (Baltink et al., 2002) introduced in Table 3 indicates that our results comparing final and predicted ephemerides are better in all. While comparing results from GPS and RDS, our results have lower bias, but the standard deviation and RMSE of our results are higher. By our opinion this result is caused by few outlier values present in such a small file we used. It has to be mentioned that older types of predicted ephemerides were used in (Baltink et al., 2002) and their lower quality has been already acknowledged by (Douša, 2004). The comparison implies that the quality of the current predicted ephemerides is at a very high level and better than it used to be.

\begin{tabular}{|l|r|r|r|r|}
\hline & Bias, $\mathrm{mm}$ & $\mathrm{SD}, \mathrm{mm}$ & \multicolumn{1}{|c|}{$\begin{array}{l}\text { RMSE, } \\
\mathrm{mm}\end{array}$} & \multicolumn{1}{|c|}{ Pairs } \\
\hline GPS final vs. predicted & -0.13 & 1.02 & 1.03 & 2430 \\
\hline GPS final vs. RDS & -0.64 & 0.92 & 1.11 & 95 \\
\hline
\end{tabular}




\begin{tabular}{|}
\begin{tabular}{|c|r|r|r|r|}
\hline GPS predicted vs. RDS & -0.84 & 1.14 & 1.41 & 79 \\
\hline
\end{tabular} \\
Table 3: Statistical Processing of the Comparison of PWV Estimation Methods According to Baltink et al. (2002)
\end{tabular}

Fig. 2 presents the quality and potential applicability of RINEX ephemerides for use in GPS meteorology. While it is possible to estimate the general development of the PWV values using the resulting values, a comparison of individual values proves that they are inapplicable for the study's purpose.

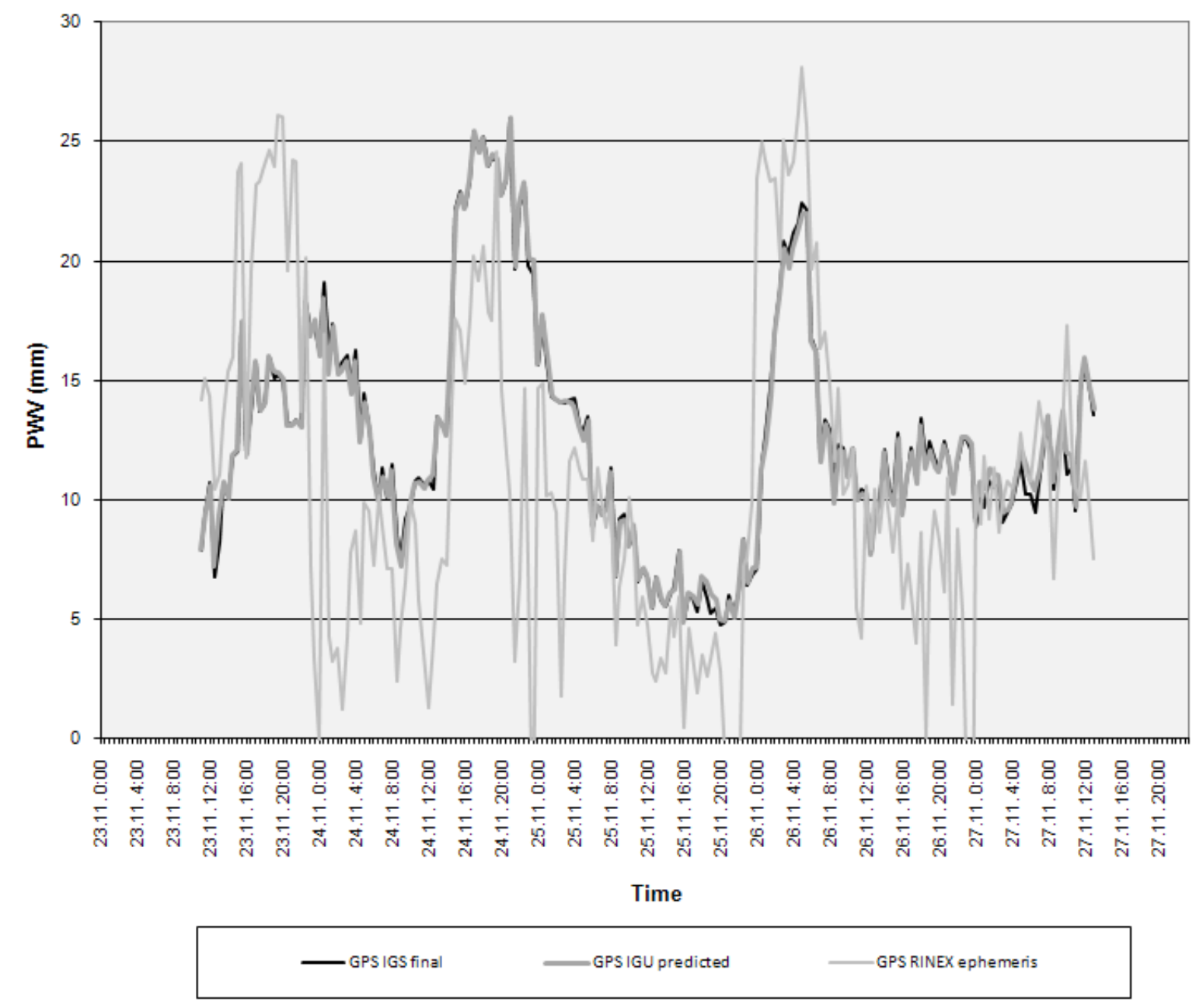

Fig. 2: PWV content in the Atmosphere based on estimations from GPS Measurements at the weather station in Praha-Libuš, $23-27$ November, 2009

Fig. 3 shows a comparison of the PWV calculations from GPS measurements at the GOPE and CHMU stations using the final ephemerides. The distance between these stations is approximately $26 \mathrm{~km}$, which can influence the results as described in Chapter 1. With few exceptions, it is evident that the PWV values during the measurement period are similar at both stations. Furthermore, a comparison of the GPS and the RDS measurements would be possible even if we did not have the GPS measurements from the meteorological station in Praha-Libušs. During the measurement period, a deep low pressure system over the East Atlantic Ocean was moving warm air from south to Central Europe. This system influenced the weather in the Czech Republic, especially in the upper layers of the atmosphere. Variable, inverse weather and moderate zonal flow in the lower layers of the atmosphere were interrupted briefly by individual frontal systems coming from the west and southwest. Increased PWV values in Figure 3 correspond to a warm front moving over the Praha-Libuš station on 24 November 2009 around 17:00 UTC and also to a cold front on 25 November 2009 around midnight. The atmospheric fronts moved toward the east and passed over the GOPE station later than over CHMU causing a slight shift in the PWV calculations from the CHMU and GOPE stations. 

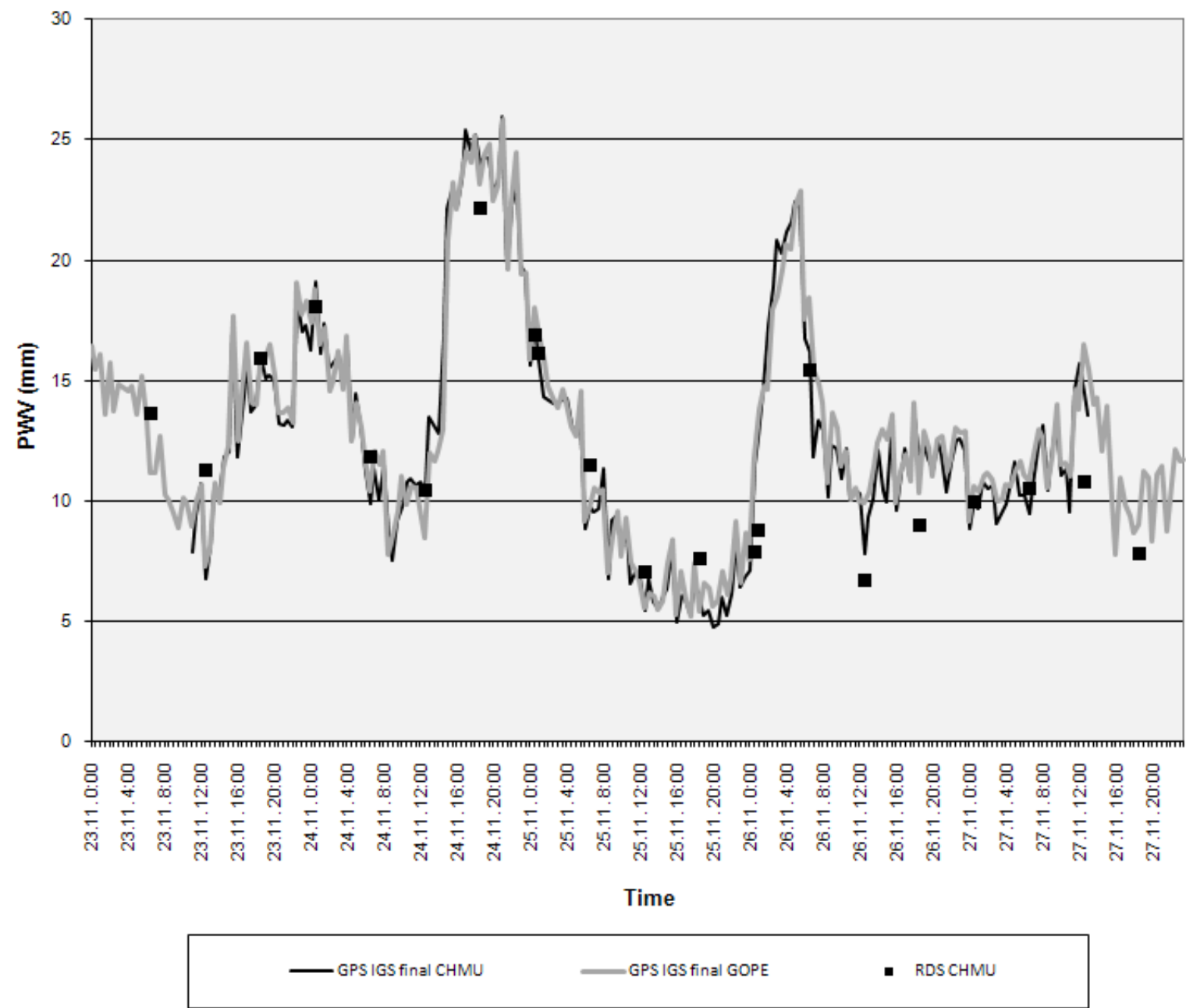

Fig. 3: PWV content in the atmosphere based on estimations from GPS measurements at the weather station in Praha-Libuš and at the GOPE Reference Station, $23-27$ November, 2009

\section{Conclusion}

The results presented here indicate a high accuracy of the PWV values, both when using final and predicted ephemerides. The predicted ephemerides provided by the IGS represent a useful source of data for the NRT GPS meteorology as shown previously by several researchers (Douša, 2001, Springer a Hugentobler, 2001). The measured results indicate that the quality of the predicted ephemerides has improved significantly. As a result of this improvement, the pre-processing methods based on eliminations of outlier values of satellite orbit parameters are no longer necessary. Thus, it is possible to use the files with the ephemerides for the ZTD calculations without prior analysis. However, more complex evaluations should be done to ensure accuracy. Measurements from a couple of days are not adequate for a long-term generalisation. The error rate of the ephemerides highly depends on the actual constellation of the GPS orbits (Douša, 2009). Furthermore, the results indicate that measurements from the temporary stabilized GPS receiver are usable for accurate ZTD estimation and can provide as precise ZTD values as those from permanent references stations.

Acknowledgement This study was financed from the project of the Students' Grant Competition $\mathrm{n}$. SP/2010149 at VŠB-Technical University of Ostrava. 


\section{References}

Baltink, K. H., Marel, H., Hoeven, A. Integrated atmospheric water vapor estimates from a regional GPS network. Journal of Geophysical Research, vol. 107, 2002.

Bevis, M., Businger, S., Herring, T.A., Rocken, C., Anthes, R.A., Ware, R.H. GPS meteorology - remotesensing of atmospheric water-vapor using the global positioning system. Journal of Geohysical ResearchAtmospheres, Vol. 97, Issue D14, pp. 15787-15801, 1992.

Dach, R., Hugentobler, U., Fridez, P., Meindl, M. GPS Bernese Software, Version 5.0. Astronomical Institute, University of Berne, Berne, 2007.

Douša, J. The impact of ultra-rapid orbits on precipitable water vapor estimation using a ground GPS network. Physics and Chemistry of the Earth, Part A: Solid Earth and Geodesy, Vol. 26, No.6-8, pp. 393-398, 2001.

Douša, J. Precise orbits for ground-based GPS meteorology: Processing strategy and quality assessment of the orbits determined at geodetic observatory Pecny. Journal of the Meteorological Society of Japan, Vol. 82, No. 1B, pp. 371-380, 2004.

Douša, J. The impact of errors in predicted GPS orbits on zenith troposphere delay estimation. GPS Solutions, DOI 10.1007/s10291-009-0138-z, 2009.

Duan, J., Bevis, M., Fang, P., Bock, Y., Chiswell, S., Businger, S., Rocken, C., Solheim, F., van Hove, T., Ware, R., McClusky, S., Herring, T., King, R. GPS meteorology: Direct estimation of the absolute value of precipitable water. Journal Appl. M., 24(24), 830-838, 1996.

Ge, M., Calais, E., Haase, J. Automatic orbit quality control for near real-time GPS zenith tropospheric delay estimation. Physics and Chemistry of the Earth, Part A: Solid Earth and Geodesy, Vol. 26, No. 3, pp. 177181, 2000.

Springer, T.A., Hugentobler, U. IGS ultra rapid products for (near-) real-time applications. Physics and Chemistry of the Earth, Part A: Solid Earth and Geodesy, Vol. 26, No.6-8, pp. 623-628, 2001. 